\title{
Observing the Microstructure of Rapidly Solidified Powders with the SEM
}

James H. Steele Jr.

Consultant, 2019 Nova Road, Pine CO 80470

A variety of solidification patterns have been observed in rapidly solidified alloys.[1] In an alloy the patterns can vary with velocity of the liquid-solid interface, which alters the ability of the alloy to partition solute between the liquid and solid phases.[2,3] Microstructural patterns have been observed to vary from; cellular, to columnar dendritic, to equiaxed dendritic, to patternless (microsegregation free) as interface velocity increases.[4] Thus rapid solidification patterns will tend to contain small compositional variations, which provide atomic number contrast for observation using backscatter electron imaging in the SEM. Observation of these microstructural patterns in rapidly solidified powders requires special sample preparation techniques that allow argon ion etching to be applied to metallographically prepared cross sections. The technique involves mounting a sample of powder in a liquid Bi-Sn alloy (e.g. Cerrotru) at $145^{\circ} \mathrm{C}$ under $10 \mathrm{ksi}$ pressure, and then allowing the liquid Bi-Sn to solidify while maintaining the pressure.[5] Standard metallographic grinding methods and final polishing with diamond paste can then be applied to obtain cross sections of even the smallest of particles in the sample. The polished metallic mount can then be argon ion etched with almost any type of argon ion beam forming apparatus.

Examples of rapid solidification patterns from a superalloy powder (Composition: $71 \boldsymbol{w} / \% \mathrm{Ni} / 8 \boldsymbol{w} / \%$ $\mathrm{Al} / 9 \boldsymbol{w} / \% \mathrm{Mo} / 9 \boldsymbol{w} / \% \mathrm{~W} / 3 \boldsymbol{w} / \% \mathrm{Cr}$.) are provided in Figures 1, 2, and 3. Figure 1 provides an inverted backscatter electron image of several particle cross sections. This powder exhibits classic columnar dendritic patterns, as seen in Figure 2, where composition of the interdendritic regions is enriched in all of the alloying elements listed. Also some submicron interdendritic shrinkage porosity can be observed on right side of the particle (bright contrast). Cellular patterns, as shown in Figure 3, are also observed, and these show evidence of a grain size of approximately $2-5 \square \mathrm{m}$.

Solidification patterns in a GTiAl alloy powder (Composition: Ti / 32w/ $\% \mathrm{Al} / 5 \boldsymbol{w} / \% \mathrm{Nb} / 1 \boldsymbol{w} / \% \mathrm{Ta}$ $/ 0.15 w / \% \mathrm{C} / 0.20 w / \%$ O) produced by a rotating disk method are shown in Figures 4, 5, and 6. Figure 4 provides a low magnification inverted backscattered image of argon ion etched cross sections of several larger particles(-80+100mesh). These coarser particles tend to have complex shapes and exhibit dendritic colonies as seen in Figures 4, and 5. Very fine internal porosity can be observed in Figure 5 (dark contrast). The finer particles from a -320 mesh separation tend to exhibit a more equiaxed dendritic morphology as seen in Figure 6.

\section{References}

[1] H. Jones, Mater. Sci. Eng., 65(1984) 145.

[2] B.H. Kear, et al., Metall. Trans. A 10(1979) 191.

[3] W.J. Boettinger, et al., Metall. Trans. A 15(1984) 55.

[4] P.N. Quested and M. McLean, Mater. Sci. Eng., 65(1984) 171.

[5] E.T. Rose and L.F. DeRoos, Microstructural Science, Vol. 1(1972) 275. 


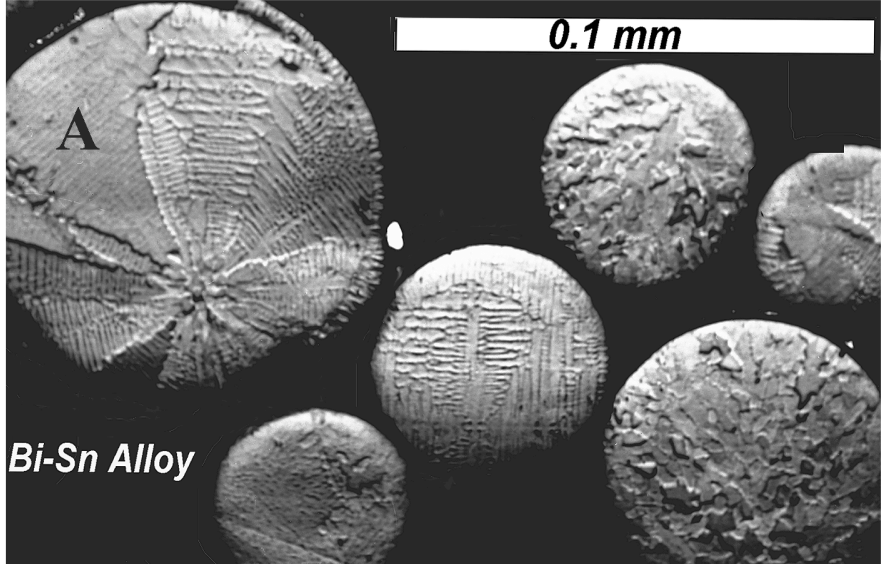

Fig.1 Superalloy Particle Cross Sections. Particle A is shown in Fig. 2



Fig. 3 Superalloy Particle w/Cellular Pattern.



Fig. 5 TiAl Particle w/ equiaxed dendritic pattern.

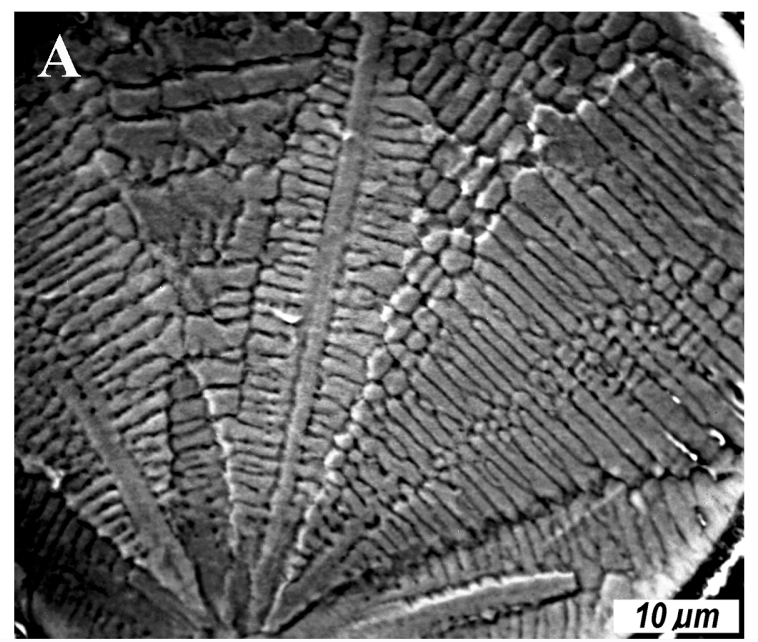

Fig. 2 Superalloy Particle w/Columnar Dendritic Pattern.

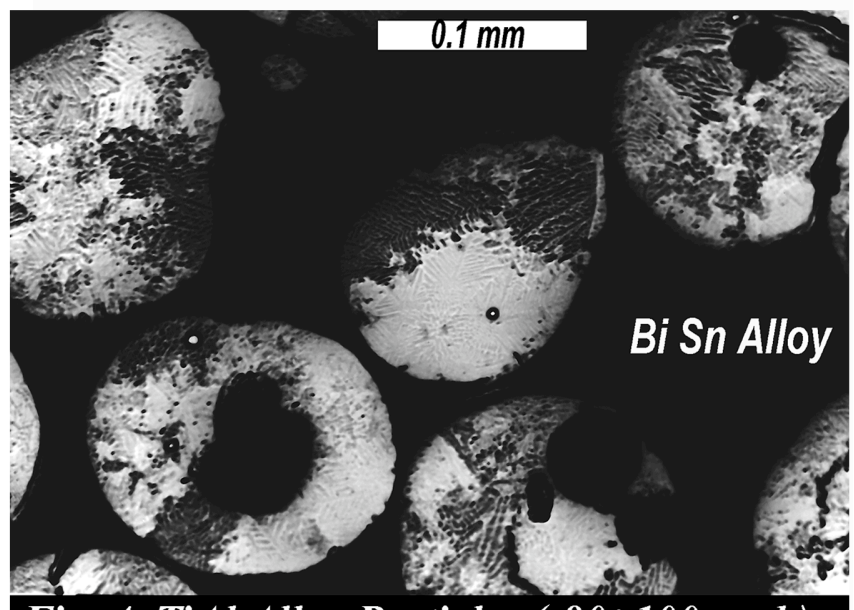

Fig. 4 TiAl Alloy Particles (-80+100mesh).

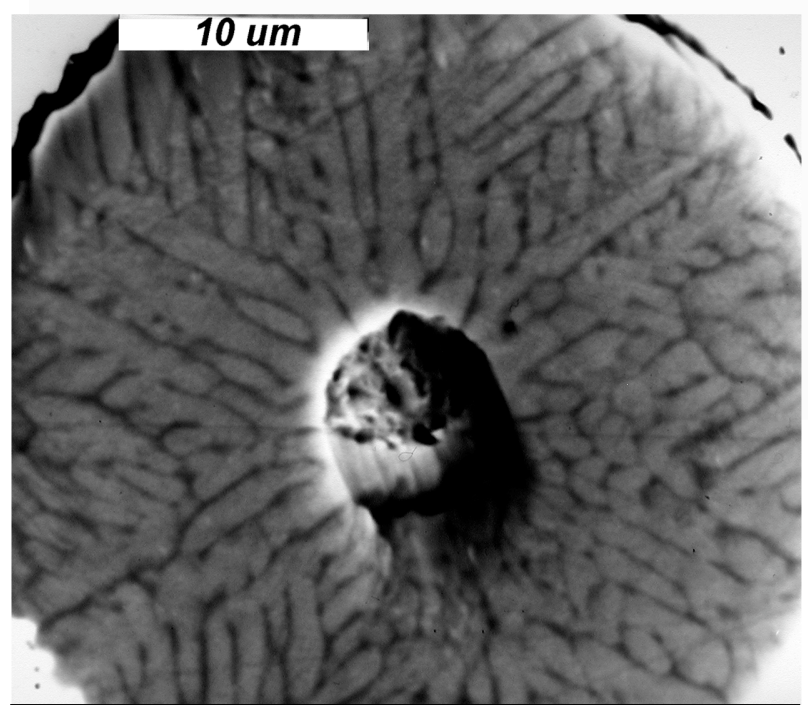

Fig. 6 -320 mesh TiAl Particle. 